\title{
O Bairro Getúlio Vargas, a remoção de moradias dos anos 1970 e a produção da desigualdade ambiental em Rio Grande-RS
}

\author{
The neighborhood Vargas, removing houses of the I970s and the production of \\ environmental inequality in Rio Grande-RS
}

\section{Diego Mendes Cipriano" Carlos Roberto da Silva Machado"}

Resumo: Neste artigo, analisamos a problemática das remoções de moradias do Bairro Getúlio Vargas entre os anos de 197I e 1973, motivadas pela expansão das atividades portuárias na cidade do Rio Grande, tendo em vista compreender como os diferentes atores se pronunciaram sobre estes acontecimentos. Buscamos apreender as consequências imediatas deste processo aos moradores deslocados para novos ou recém-criados bairros da cidade. Evidenciamos que a remoção das moradias do BGV no início da década de 1970 consistiu num processo marcado por contradições que configurou um cenário de segregação espacial, desenraizamento cultural e precarização das condições socioambientais daqueles moradores. Assim, apontamos para uma mudança na forma com que os educadores e gestores ambientais poderão conceber e praticar futuros eventuais processos de remoção de casas em áreas portuárias, de modo a considerar os moradores como portadores do direito ao desfrute de seus territórios. Isto porque, à luz de uma Educação Ambiental crítica e transformadora, conceber e praticar a vida em seus diversos contextos socioambientais é o mesmo que garantir e respeitar o direito das populações desenvolverem livremente suas potencialidades numa perspectiva de participação e cidadania plena que contribua à emergência gradativa de um novo modelo de desenvolvimento includente, promotor da cidadania e da sustentabilidade às gerações atuais e futuras.

\footnotetext{
${ }^{\mathrm{I}}$ Este artigo é uma síntese da pesquisa de mestrado intitulada O Bairro Getúlio Vargas e a grande faxina dos anos "Historiador e Mestre em Educação Ambiental pela Universidade Federal do Rio Grande - FURG.

"Doutor em Educação pela Universidade Federal do Rio Grande do Sul - UFRGS.
} 
Palavras-chave: História; remoção de moradias; Bairro Getúlio Vargas; Educação Ambiental.

\begin{abstract}
This article analyzes the problem of removals Vargas Neighborhood houses between the years 197I and 1973, driven by the expansion of port activities in the city of Rio Grande, in order to understand how different actors have spoken about these developments. We seek to grasp the immediate consequences of this process for the displaced residents to new or newly created districts of the city. We showed that the removal of BGV dwellings in the early I970s consisted of a process marked by contradictions that have set up a spatial segregation of scenery, cultural uprooting and precarious socio-environmental conditions of those residents. Thus, we point to a change in how educators and environmental managers can design and practice possible future homes removal processes in port areas, in order to consider the residents as having the right to enjoy their territories. This is because, in the light of an environmental education and critical manufacturing, design and practice life in its various environmental contexts is the same as guaranteeing and respecting the right of people freely develop their potential in a prospect of participation and full citizenship to contribute to the gradual emergence a new model of inclusive development, citizenship and promoter of sustainability for present and future generations.
\end{abstract}

Keywords: History; removal of housing; Neighborhood Getúlio Vargas; Environmental Education.

\title{
A expansão portuário-industrial no contexto da globalização capitalista: território e injustiça ambiental em Rio Grande
}

Sob o ponto de vista do materialismo histórico, perceberemos que a trajetória humana irá conduzir a gradativa separação entre sociedade e natureza, consumando-se com o advento do trabalho assalariado e do modo de produção capitalista. Sendo assim, a partir da década de 1970, o desenvolvimento científico e tecnológico irá potencializar a já existente acumulação de capital, constituindo aquilo que David Harvey (I993) chamou de 
"modo de acumulação flexível", em que os processos produtivos, voltados à mais-valia global, adquirem um caráter extraterritorial que sobrepuja os limites locais e ambientais.

Desse modo, ações, projeções e decisões quanto ao projeto de expansão do setor portuário industrial da cidade do Rio Grande devem ser compreendidos dentro de um caráter extraterritorial - como é o caso do Superporto e do Distrito Industrial - nos processos de tomada de decisão em contraposição à "territorialidade localizadora" da cidade do Rio Grande, já que a mesma constitui-se em "enclave marítimo-continental” situada em "zona de fronteira consolidada" (DOMINGUES, I997, 6).

É neste sentido que Domingues (1997) aprofunda o seu olhar de cunho estratégico e desenvolvimentista, situando o porto e as questões relacionadas ao seu entorno como fruto de decisões que ultrapassariam a escala imediata e, portanto, relativas a uma magnitude escalar que sobrepuja o "particularismo" dos locais, e neste caso, daqueles que necessitariam ser continuamente removidos à ampliação das atividades portuárias. $\mathrm{Na}$ perspectiva deste autor, deveria ocorrer um planejamento pautado pela imediata remoção das localidades envolvidas no processo de implantação e expansão do setor portuárioindustrial de Rio Grande.

Para ele, o Porto do Rio Grande é e continuará sendo construído “independente da vontade dos rio-grandinos", por ser estratégico numa rede de transportes capaz de conectar distintos lugares do globo terrestre. Tal seria a "extraterritorialidade" dos portos marítimos, e neste caso o da cidade do Rio Grande, que inviabilizaria as ações de resistência e reivindicatórias das localidades atingidas pelo processo de expansão em curso, e que protagonizam "conflitos de uso" neste cenário desenvolvimentista.

É desta forma que a partir da necessidade imperativa do desenvolvimento e do progresso econômico, ocorreu o deslocamento de grandes contingentes populacionais de seus territórios, o que vem beneficiar determinados grupos econômicos e políticos, denotando um processo histórico marcado pela injustiça ambiental na cidade. Ou seja, em determinado momento, estas pessoas são removidas para outras áreas longínquas, à medida que seus terrenos, antes desvalorizados, ganham importância diante do contexto

\footnotetext{
${ }^{2}$ Segundo D. Harvey, este constituirá, entre as décadas de I970 e I980, as novas características do capitalismo mundial, ou seja, a flexibilidade das leis trabalhistas, das normas de fiscalização das empresas, dos processos de privatização, ofensiva contra do Estado (regulamentações, normas e fiscalização, etc.) e tudo que pudesse impedir a livre circulação de mercadorias. No núcleo destas transformações, o tempo de produção e vida das mercadorias é reduzido drasticamente e, em conseqüência, a competição é elevada a níveis sem precedentes; ao mesmo tempo, o espaço de produção, comercialização e fontes de matérias-primas transforma-se no espaço mundial. No caso da natureza física, ela é reduzida à "recursos naturais", ou seja, é ampliada à exploração do ambiente natural e sua transformação em mercadoria. Tudo isso terá implicações culturais caracterizadas pelo autor como "pós-modernas", sendo estas decorrentes deste "modo de acumulação flexível".
} 
econômico e dos poderosos interesses capitalistas em expansão. Neste sentido, as lutas por justiça ambiental seriam aquelas em que determinados grupos pretendem ser sujeitos de seus ambientes de vida, assegurando seus direitos e modos de vida consolidados. (ACSELRAD et al, 2009: 129).

Do ponto de vista da ecologia política, o território é compreendido em termos das relações de poder dos atores sociais e de suas "práticas socioespaciais", em distintas escalas geográficas. Esta perspectiva é defendida por Sérgio Ulisses Silva Jatobá (2009, p. 74), para quem a disputa por recursos travada por atores sociais com condições desiguais de poder, movidos por interesses e objetivos distintos - e até mesmo antagônicos - ocasiona conflitos socioambientais que condicionam a forma com que territórios são ocupados, assim como as modificações ambientais por que passam. No que concorda Ícaro da Cunha (2006, p. IOI9-IO2O), para quem os portos são indutores de "transformações territoriais em ampla escala", ensejando uma gama de conflitos ambientais que envolvem diversos atores em torno dos problemas ocasionados.

\section{O território do Bairro Getúlio Vargas: panorama da "grande faxina" dos 1970}

Nos anos 1960, com o fechamento da Companhia Swift, a cidade do Rio Grande adentrou em um quadro desfavorável no relativo ao desemprego causado por este fato, ampliando-se o quadro de miserabilidade das condições precárias de vida de muitas pessoas, e também o consumo de drogas e a prostituição.

A partir desta década, a imprensa abordará firmemente estes problemas, em páginas recheadas com diversos tipos de ocorrências, tais como os roubos, arrombamentos e episódios de agressões físicas, então muito comuns àquele momento da história citadina, e que tinham a Vila do Cedro - ou Bairro Getúlio Vargas - como o seu palco. (OLIVEIRA, 2000: 215). Não é difícil imaginarmos, de antemão, que esta realidade de prostituição e tráfico e/ou consumo de substância ilícitas - fomentada pela falta de perspectivas de trabalho e renda - serviram como fonte de legitimação e propaganda governamental e midiática em favor de todo um processo de "higienização" social que apregoava a remoção das chamadas "malocas" no BGV, vistas como responsáveis pela degradação dos citadinos e a instabilidade social e política.

Tais problemas acabariam por se constituir em justificativa para que a zona portuária - e mais especificamente o Bairro Getúlio Vargas - sofressem uma série de intervenções por parte das autoridades, no sentido de uma "limpeza" dos elementos indesejados e a liberação de áreas para a expansão do Porto do Rio Grande. Neste caso, 
serão retomadas as tentativas de remoções ocorridas em décadas anteriores, mas agora dentro de um quadro muito mais amplo, pois que envolvia um grande contingente populacional e uma organização complexa como suporte à política de "racionalização" do espaço.

Todavia, reiteramos que tais fatos devem ser compreendidos no contexto dos “interesses nacionais" de ampliação do desempenho das atividades portuárias, motivo pelo qual se recomendava o afastamento de elementos duvidosos daquela localidade para bem longe da zona portuária. Sendo assim, se articulou o intento de alijar a precariedade representada pelas malocas à "boa sociedade" e à "estabilidade social" através da retirada dos moradores daquele território; com o desenvolvimento almejado pelo país, em que o Porto do Rio Grande assumia papel central em sua concretização no "bom andamento dos serviços" e na "formação da índole portuária". (OLIVEIRA, 2000, p. 22I-222).

A remoção das moradias liberaria espaços à abertura de ruas, à construção de silos e armazéns e à edificação dos próprios estabelecimentos portuário-industriais necessários aos grupos econômicos que aí poderiam se instalar. Para o Porto do Rio Grande, era uma oportunidade clara e indispensável ao incremento de sua movimentação comercial e ampliação das exportações. Mas tudo isso causava problemas e perspectivas aos que ali moravam:

A questão da remoção das casas, tem uma espécie de duplo significado. Se por um lado a remoção significou, numa primeira leitura, o afastamento de um grande número de trabalhadores portuários das cercanias de seu ambiente de trabalho, dissociando as funções de morar com trabalhar. Por outro lado, como se tratavam de ocupações irregulares, a transferência/remoção significava a possibilidade de conquista de um terreno próprio, escriturado [...] (OLIVEIRA, 2000, 222).

Entretanto, mesmo ante os aspectos positivos trazidos pela remoção das moradias, que dizem respeito estritamente a questões jurídico-legais como títulos de propriedade, é inegável que toda esta mudança territorial que elas traziam, colocava em questão toda a vida material e simbólica edificada pelos moradores do BGV durante décadas, o que representava a ruína de todo um universo construído e prenhe de significados para os seus habitantes. Para termos uma dimensão aproximada da amplitude da remoção das moradias, é altamente ilustrativo que entre maio de I97I e março de 1973 - isto é, em menos de dois anos - foram removidas aproximadamente Iooo moradias, incluindo cantinas, 
bares e boates do entorno do Porto Novo para bairros muito distantes daquelas imediações, causando enorme transformação da área portuária (OLIVEIRA, 2000, 223). Neste processo de grande amplitude e impacto:

Do anúncio das remoções, passando pela mudança, onde casebres de madeira atravessam a cidade ${ }^{3}$, em cima de triângulos puxados por tratores, 'Trojan'. Os então moradores experimentam situações bastante tensas e, em alguns casos, constrangedoras. A presença dos funcionários do DEPREC era acompanhada de pânico e pavor, para grande parcela de moradores. Isto em função da entrega da notificação pelos funcionários do DEPREC, dando ciência que em poucos dias, os 'invasores' teriam que ser removidos. [...] (OLIVEIRA, 2000, 223).

Para evidenciarmos a dimensão da transformação nas relações das populações que viviam naquele território, e, portanto, das possíveis rupturas materiais e simbólicas, na tabela abaixo apresentamos dados das populações removidas no período de I97I a I973.

Tabela: Remoção de casas (1971-1973) Bairro BGV, Rio Grande

\begin{tabular}{|l|l|l|}
\hline ETAPA & PERI & 86 casas \\
\hline$I^{\text {a Etapa }}$ & I97I & 264 casas \\
\hline $2^{\text {a }}$ Etapa & 1972 & 83 casas \\
\hline $3^{\text {a }}$ Etapa & 1972 & 172 casas \\
\hline $4^{\text {a Etapa }}$ & I972/73 & 359 casas \\
\hline $5^{\text {a }}$ Etapa & Maio 7I - março 73 & $\mathbf{9 6 4}$ casas $^{4}$ \\
\hline TOTAL &
\end{tabular}

FONTE: Biblioteca da SUPRG, in Oliveira (2000: 223). Adaptado por Diego Cipriano

Podemos ver que na área correspondente ao Porto Novo - mais especificamente o Bairro Getúlio Vargas - a cada ano, em torno de 250/300 famílias, e no curto espaço de três anos, o total de 964 famílias, em torno de aproximadamente 4 mil pessoas, foram

\footnotetext{
${ }^{3}$ Conforme nos esclarece Solismar Martins, a recorrente expressão "remoção de casas" é utilizada no sentido de que estas moradias eram sempre de madeira, e que por isso, um fato muito comum, mas décadas de 1960 e 1970, era a remoção de casas inteiras que eram conduzidas pelas ruas de Rio Grande do seu local de origem até os terrenos para os quais eram destinadas. Ele acrescenta que nestas operações, retiravam-lhes as telhas de barro por estas representarem um peso considerável ao seu transporte. (MARTINS, 1997: 42).

${ }^{4}$ Não é por acaso que Carlos Alberto de Oliveira, em sua tese de doutorado Quem é do mar não enjoa: Memória e Experiências de Estivadores do Rio Grande/RS (1945-1993), cunhará o termo "grande faxina" para significar a amplitude e a intensidade do processo de remoção das moradias e moradores do BGV. (OLIVEIRA, 20oo: 2I5).
} 
removidas com suas respectivas casas, de seu território e modos de vida partilhados em nome do desenvolvimento. E considerando que tal processo se estendeu até os anos 1980 , a dimensão do problema social poderia até mesmo ser considerada de maior gravidade.

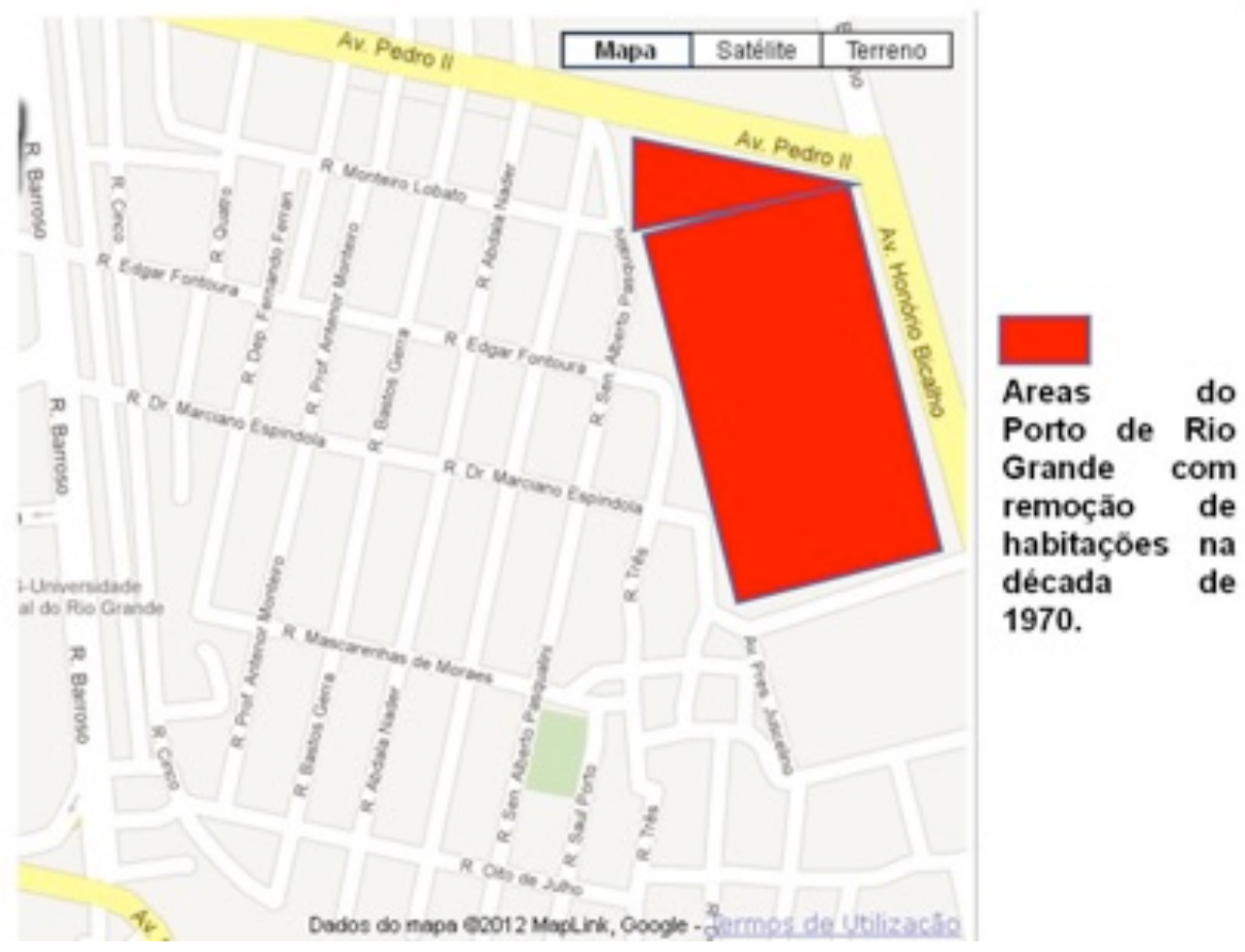

Fonte: Google Earth. Imagem gerada em 10.07.2012. Adaptado por Diego Cipriano.

Neste artigo, no entanto, focaremos especificamente no período de I97I a 1973. Dentro deste recorte espaço-tempo, os terrenos destinados aos removidos, em outras localidades da cidade, eram adquiridos com recurso financeiro doado pela SAMRIG (Sociedade Anônima Moinhos Rio-Grandenses) à SORAN - Sociedade Rio-grandina de Auxílio aos Necessitados, que se responsabilizava da compra e do pagamento das respectivas escrituras das novas moradias aos ocupantes de novos terrenos. 
Figura 5: Trabalhadores retirando telhas de casa a ser removida, e posteriormente puxada pelo trator.

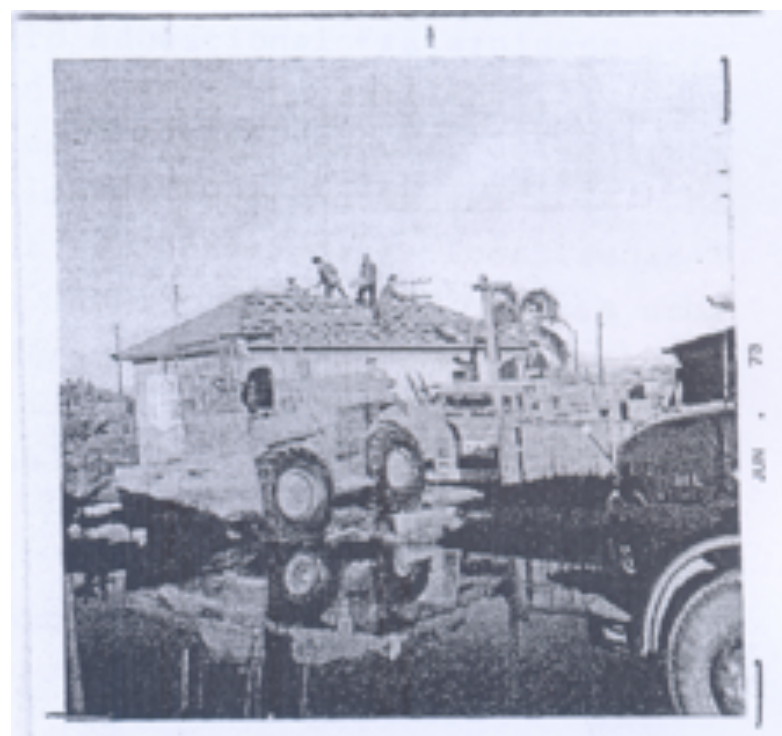

Na medida em que, de um lado, se retiravam famílias da área do Porto Novo e as liberava para a ocupação de empreendimentos econômicos, de outro lado, as populações deslocadas contribuíram para a ocupação de outros terrenos, com a origem e/ou crescimento de outros bairros de Rio Grande, sendo um exemplo a chamada Vila São João. (OLIVEIRA, 2000: 227-229). Neste aspecto, um dos problemas que se colocava a partir da remoção das moradias para zonas distantes da urbe, era o do

deslocamento diário dos moradores-estivadores removidos até o seu local de trabalho, como anunciamos anteriormente. Para isso, algumas medidas pontuais foram tomadas para, ao menos, suavizar o problema:

\footnotetext{
Visando minimizar os deslocamentos dos estivadores e demais trabalhadores do Porto, foram criadas novas linhas de Transporte Coletivo, como a Linha Polivalente (Rheingantz e Portugal), que ligam a Vila São João e o Porto Novo, cruzam a Vila dos Cedros (BGV) e dirigem-se até a Vila São João, em seus trajetos, cruzam outros tantos bairros que surgem após a remoção das casas da Vila dos Cedros. A Linha Rheingantz possui 23,3 Km e a Linha Portugal possui 24,9 Km de extensão. (OLIVEIRA, 2000, 229).
}

Acreditamos que as medidas compensatórias acima citadas eram de caráter pontual e visava tão somente atenuar os reflexos trazidos pelas remoções às pessoas que trabalhavam próximas ao Porto Novo, no território do Bairro Getúlio Vargas, e que de agora em diante se encontravam muito afastadas destas imediações. Além disso, o problema gerado não era exclusivamente no que tange ao ir-e-vir para o trabalho no Porto, pois que o problema, além de comportar questões de caráter social e econômico, também perpassava elementos culturais de identificação daqueles moradores-trabalhadores com o seu antigo modo de vida como um todo. É aqui que César Martins corrobora as descrições e análises realizadas por Oliveira (2000), de que nos utilizamos anteriormente, explicitando 
um entendimento mais abrangente das remoções e suas repercussões aos moradores por ela atingidos:

\begin{abstract}
A distância do trabalho na beira do cais afastava não somente os trabalhadores de suas moradias, mas também dos rituais que envolviam o ir e vir pelas ruas do centro e especialmente da Vila do Cedro (atual Bairro Getúlio Vargas), limítrofe ao Porto Novo com suas moradias autoconstruídas e toda uma riqueza cultural. [...] (MARTINS, 20II, 73).
\end{abstract}

Assim, não foram removidas apenas casas, mas também com elas, projetos de vida e todo um universo material e simbólico dotado de singularidade para os moradores do Bairro Getúlio Vargas. É por isso que César Martins, ao refletir sobre as remoções das moradias da zona portuária, no contexto da atualidade, realiza um apanhado histórico das também efetuadas em épocas passadas, mais especificamente no contexto dos anos 1970, corroborando os pressupostos que aqui levantamos. Afirma ele de maneira muito clara:

[...] Partimos do princípio que moradores são pessoas que moram. Morar contém o habitar como outros seres vivos e agrega as dimensões humanas de suprir a necessidade de proteção para repor energias e as dimensões do desejo de identificação e reconhecimento. A concretude é que aqueles moradores moravam e moram em áreas portuárias e com todas as vicissitudes das suas condições de moradia, eles não apenas habitam, mas moram. (MARTINS, 20II, p. 9I).

Aqui, César Martins estabelece uma nítida diferenciação entre o "habitar" e o “morar”, estando a primeira noção identificada com a mera ocupação material do território por pessoas que ali existem, enquanto que a segunda diz respeito a algo maior e ainda mais significativo à compreensão de nosso trabalho, isto é, à totalidade dos vínculos materiais e simbólicos estabelecidos pelos moradores com o seu lócus de vida, com todos os sentidos existenciais de que estão permeados. Nesta lógica, as remoções teriam ocorrido de maneira forçada e sem nenhuma espécie de diálogo aberto com os moradores envolvidos. Em decorrência estas pessoas foram obrigadas a serem deslocadas de sua "área de convívio" para zonas da cidade que não contavam praticamente com nenhuma condição de sobrevivência, incluindo terrenos da Vila São João e Vila São Miguel, o que trouxe um significativo desenraizamento dos mesmos. (MARTINS, 20II, p. 94-95; 87 e Io6). 


\section{A Remoção das moradias do Bairro Getúlio Vargas de 1971 a 1973: reconstruindo o cenário e as consequências no processo histórico}

Ao final do mês de junho de 1971, o jornal Rio Grande veiculou, em sua contracapa, descontentamentos dos moradores com a retirada das casas do Bairro Getúlio Vargas. Nesta matéria, intitulada Há descontentamento quanto a transferência das casas da Av. Honório Bicalho, consta que as remoções das moradias causam apreensões em lideres de varias entidades e de pessoas diretamente atingidas pelas mudanças em curso, como segue:

Acontece que os moradores daquela faixa de terra a ser desabitada, são transferidos para a zona dos Carreiros, em local não bem apropriado para tal fim com enormes prejuízos materiais e monetário (sic), pois os poderes públicos não vem dando a importancia a necessária assistência a tal serviço pois as casas são tiradas do bairro Getúlio Vargas, muitas já desmontadas, e simplesmente largadrs (sic) no local de sua nova localização sem que seja dada uma maior assistência ao seu proprietário 5 .

Verificamos, portanto, que as localidades para onde foram removidas as moradias retiradas do BGV não estavam em condições básicas de habitação, já que as residências eram simplesmente depositadas em seus terrenos de destinação, conforme a matéria jornalística supracitada.

Neste sentido, é dado destaque a uma reunião entre entidades classistas dos portuários com a municipalidade, visando discutir e buscar uma solução ao problema vivenciado pelos moradores: “[...] Alegam aqueles moradores que a mudança de casas, da maneira como vem sendo procedida, vem causando sérios transtornos aos atingidos pela medida, sendo, até, deshumana [...]" . E assim se manifestou o dirigente da Sociedade Amigos do Bairro Getúlio Vargas, Sr. André Alves de Oliveira: "nós os dirigentes classistas não somos contra a retirada das casas, em absoluto. Não queremos entravar o progresso. Queremos isso sim, que não se venha a criar um novo cedro nas proximidades dos Carreiros". ${ }^{7}$ Desta forma, o dirigente do bairro teria expressado preocupação com as conseqüências que as remoções poderiam produzir às novas localidades que estavam sendo ocupadas com as casas removidas. Também, segundo a matéria:

\footnotetext{
${ }^{5}$ Jornal Rio Grande. 23 de junho de I97I, n.I65. Há descontentamento quanto a transferência das casas da Av. Honório Bicalho. (p.8 - contracapa).

${ }^{6}$ Idem.

${ }^{7}$ Idem.
} 
O presidente da Sociedade Amigos do Bairro Getúlio Vargas, disse nos, ainda, que um dos grandes prejudicados com a transferência das casas para tão longe foi o próprio pôrto pois diversos trabalhadores que soltam do serviço as I9 horas não poderão voltar a trabalhar na mesma noite, pois quando soltarem novamente não poderão ir para casa pois residindo nos Carreiros não haverá mais condução. Segundo apuramos também, vários dêles já estão dormindo nos porões dos navios, nos armazéns ou então ficam perambulando pelas boates a fim de aguardarem que amanheça para outra vez trabalharem ${ }^{8}$.

Conforme relata o periódico, outra consequência negativa da remoção das moradias reside nos problemas de locomoção que os moradores removidos do BGV para os seus novos locais de destinação, estavam vivenciando desde então, com uma piora qualitativa nas condições de trabalho destes obreiros portuários em função de problemas de transporte do trabalho para suas novas residências.

Neste sentido, no intuito de compreender a dramaticidade do processo de retirada destas moradias, fazemos referência a um episódio sobre a remoção de um estabelecimento comercial, desta vez um armazém, mencionado pelo inspetor-chefe Sr. João da Silva, quando de seu trabalho no serviço de remoção das moradias do BGV. Sobre o mesmo, assim se expressou o antigo inspetor:

[...] eu peguei um purtuguês aí...tinha uma armazém...e ele, todos dias que nós chegava lá, como é seu Manuel? È, hoje num dá, por isso, por aquilo... Foi indo, foi indo, até que um dia... eu disse pro capataz: ... Valdemar! ...(inaudível)...já começamu...as telha avuá lá de cima pra...pro caminhão. Tinha dois homi no caminhão e o Valdemar lá em cima...(inaudível)...ó...tiramu todo telhado do armazem e lavamu pra garage, e mais alguma coisa qui ele quisesse levá. Eu ofereci lona pra botá...pra tapá o forro. Disse: não eu não quero, porque isso, porque aquilo! Tudo bem! Mas pode chuvê, seu...seu Manuel! Não, não interessa, porque seis vão pagá, por que... Tudo bem, seu Manuel! Chuveu, caiu um temporal, molhô tudo dentro do...lá dentro do armazém! Aquela sacaria qui ele tinha: arroz, feijao, acucar...tudo! Tudo molhado! (SILVA, 20II).

\footnotetext{
${ }^{8}$ Idem.
} 
Percebemos no relato várias tentativas do proprietário do armazém em adiar o prazo para a remoção de seu estabelecimento, até o momento em que o inspetor João toma a decisão definitiva de removê-lo. Notamos nesta narrativa a ênfase no frenético trabalho de remoção de uma moradia, neste caso um estabelecimento comercial, entrevendo toda a rotina de preparo até que este fosse suspenso e colocado na estrutura que iria transportá-lo aos arrabaldes da cidade do Rio Grande.

É neste mesmo episódio que o inspetor teria alertado o proprietário à necessidade de forrar o armazém para o transporte, devido a possibilidade de chuva, tendo o mesmo se recusado a fazê-lo. Diante disso, ocorreria o lamentável incidente de uma chuva que provavelmente infligiu duras perdas econômicas ao dono do armazém. Necessário é acrescentar que, conforme o entrevista do Sr. João da Silva sobre o ocorrido, o proprietário entrara na justiça pedindo indenização pelos danos causados: "[...] O homi veio aí com o adevogado. Não conseguiram nada! [...]" (SILVA, 20II). E continua o antigo inspetor o seu relato sobre o episódio:

[...] Nem tinha porque ganhar, né... não era culpa nossa! Foi culpa dele! O homi...o homi num queria saí, de jeito nenhum! Quando a gente tomô a medida certa, que era removê a casa, fosse o que fosse... choveu! Não foi culpa minha! Eu ofereci lona... se eu não tivesse oferecido lona, até minha consciência poderia...não me deixá tranqüilo, né...mas não, eu...ofereci...eu...fiquei com pena do homi! Ele mora lá na... na Ernesto Buchholz...mais ou menos na Rural alí, pela Rural alí, ele...nós botamo a venda dele e ainda...há pouco tempo ainda tinha lá a venda. (SILVA, 2OII).

O entrevistado parece demonstrar certa preocupação em esclarecer que não fora responsável pelo lamentável episódio da chuva com a conseqüente perda material para o dono do armazém, já que segundo informou, o mesmo teria oferecido lona para cobrir o estabelecimento durante o seu transporte, tendo-se negado o proprietário. Não fazemos objeções quanto à sinceridade e a preocupação do antigo inspetor em realizar a remoção deste estabelecimento da melhor forma, conforme o seu entendimento e limitações de alguém imerso em seu contexto histórico. Neste sentido, a ênfase que o inspetor confere ao fato de ter tomado "a medida correta" relaciona-se à própria lógica da condução dos trabalhos de remoção das moradias no menor tempo possível e de modo que suscitassem a menor oposição possível dos moradores envolvidos. Entretanto, diante do exposto, não 
seria difícil inferir que muitos episódios de remoção das moradias foram acompanhados com descontentamento e oposição por parte dos moradores do bairro.

$\mathrm{Na}$ esteira dos acontecimentos relativos à remoção das moradias do BGV, o Jornal Rio Grande veicula matéria ${ }^{9}$ ainda sobre o descontentamento dos moradores que estavam sendo removidos da zona portuária - mais especificamente do Bairro Getúlio Vargas. Na notícia, encontramos a seguinte informação:

Já chegando ao fim a tarefa de transferir as moradias da area pretendida por uma empresa industrial no bairro Getulio Vargas, surge a primeira manifestação pública de descontentamento dos atingidos. Pela palavra do presidente de sua associação de amigos os que saírem do bairro Getulio Vargas, e os poucos que ainda terão de sair vem dar uma qualificação deshumana à maneira pela qual o problema foi resolvido pela Prefeitura Municipal e pelo DEPRC alegando falta de cuidado na instalação das casas em seu nôvo terreno, falta de condições de habitabilidade e até o inconveniente da localização muito distante do pôrto, onde a atividade de trabalho é exercida pelo morador.

Apesar disso, esta não foi a primeira manifestação de descontentamento dos moradores removidos do BGV, uma vez que o mesmo veículo de informações, em matéria de 23 de junho de I97I - como vimos anteriormente - veiculou os protestos do presidente do BGV que se manifestou sobre o assunto em busca de soluções para os inconvenientes. $\mathrm{Na}$ ocasião, como já referido, ele se referia à forma com que as casas eram transportadas, a precariedade dos novos terrenos de destinação e a distância das novas localidades em relação ao porto, em que muitos moradores ainda trabalhavam.

Todavia, visão bem diferente destas notícias apologéticas pode ser apreciada num sucinto entrevista de Vladimir Guimarães, antigo morador do bairro, segundo o qual a remoção das casas para zonas distantes da cidade era vista com muito pesar pelos moradores. Neste aspecto, o citado morador relata suas impressões sobre este fato tão dramático para milhares de pessoas na década de 1970, quando ainda vivia naquele território. Diz ele:

Me lembro... me lembro deles levantando as casa ai. Me lembro da tristeza que dava isto nas pessoas... o cara gostava de morar aqui... nem que ele fosse morar em lugares melhores... mas dava tristeza, o pessoal era

\footnotetext{
${ }^{9}$ Jornal Rio Grande, 25 de junho de I97I, n. I67. Levantamento Necessário (p.2).
} 
arraigado com o lugar aqui. O pessoal gostava muito do local que mora... e todo o tempo eu morei perto do Porto e dava tristeza. Eles levantavam as casas e botavam nus triângulos e atravessavam a cidade e iam primeira até aquela volta da Profilurb e depois iam prá Santa Rosa... era uma tristeza... ${ }^{\text {Io }}$

É assim que o antigo morador menciona sua tristeza quando das remoções das casas, do momento em que eram retiradas, passando por seu transporte e finalmente realocação em terrenos distantes do centro urbano. Estas considerações que ele faz nos demonstram que todo o sentimento de vinculação em relação ao território do BGV, prenhe de sentidos existências, conforme depreendemos do relato eram desconsiderados pelos agentes hegemônicos deste processo. Na melhor das hipóteses, as autoridades buscavam resolver questões mais atinentes às condições materiais dos terrenos e de sua infraestrutura, ainda que de forma insuficiente.

Assim, nem encontramos notícias que buscam retratar problemas de infra-estrutura dos novos terrenos, como a que aborda a necessidade de extensão da rede elétrica que se fazia necessária devido ao repovoamento de novos espaços ocasionado pelas remoções das casas do BGV, como segue:

[...] Atualmente, a CEEE vem desenvolvendo um trabalho difícil, que é o de atender aos consumidores que vão sendo removidos do bairro Getúlio Vargas. Quando a concentração dessas moradias se faz em bairros já existentes, a solução do problema é mais simples, pois as plantas são fornecidas pela Prefeitura e permitem à CEEE a elaboração rápida do projeto de instalação. Contudo, muitos consumidores que saem do bairro Getúlio Vargas ficam espalhados, indo, inclusive, para zonas em que não há, ainda, rêde elétrica estendida, o que acarreta dificuldades. [.... $]^{\mathrm{II}}$

Tal fato parece reforçar o argumento de que a remoção das moradias do BGV se processou de forma muito rápida ao ponto de não contar com um planejamento racional e adequado de todos os seus processos, mormente o de (re) povoamento de áreas longínquas da cidade, que não contavam com infra-estrutura alguma. Ao final das contas, os moradores são os maiores prejudicados, pois enfrentariam problemas mais elementares relacionados à sobrevivência material no ambiente urbano.

\footnotetext{
${ }^{\text {Io }}$ Entrevista de Vladimir Guimarães - I9.IO.1999. Cedido por Carlos Alberto de Oliveira em julho de 20II.

II Jornal Rio Grande, 2I de fevereiro de 1973, n.68. CEEE inicia terceira etapa de renovação da rede elétrica. (p.8).
} 
No mesmo sentido o vereador Athaydes Rodrigues coloca uma série de problemas concretos e cotidianos que os moradores estariam enfrentando nos novos terrenos a que foram destinados e removidos:

[...] se perguntarem a esses trabalhadores agora se estão satisfeitos no novo local, com água invadindo suas casas, com barro até meio da canela, sem água encanada, com transporte caro, responderão negativamente. Finalizando, disse que é justo que se dê local para as índustrias (sic), que gerarão empregos e riquezas, mas não se deve esquecer o principal que é a saúde dos trabalhadores, e o seu bem estar ${ }^{12}$.

Em tom semelhante manifestou-se o vereador Valdomiro Rocha Lima, que teria recebido o presidente da Vila São Miguel, o qual na ocasião teria revelado que aquela localidade encontrava-se em total abandono. E para agravar o quadro, é para lá que seriam transferidas cerca de 600 casas do Bairro Getúlio Vargas no contexto de remoção das moradias. O vereador, a partir de diálogo com a liderança do bairro afirma:

[...] Mas não existe luz, água encanada, esgotos. O que existe lá, e esta Casa já solicitou providências para o seu aterramento, é a tal "lagôa do Jacaré", que constitui um foco de mosquitos. Disse que a CEEE prontificou-se a estende (sic) rede eletrica naquele local se a Prefeitura delineasse as ruas com moirões de pedra; mas o Município não dispõe desses moirões, e então os moradores compraram os mesmos e estão depositados na Casa do referido Presidente. Apesar de cientificada que os moirões já estão a disposição, a Prefeitura nada fez, impedindo que aqueles moradores possa ter (sic) luz em suas residências. [.... $]^{13}$

A falta de energia elétrica e de abastecimento de água nas localidades que receberam as moradias e os moradores era muito comum. É assim que os atores envolvidos no debate das questões relativas à remoção das moradias buscam, sutilmente, livrar-se de toda a responsabilidade sobre o processo, de modo a encontrar culpados quase sempre na figura de um "outro" que nunca é mostrado com clareza.

Especificamente em relação à distância das localidades para as quais estavam sendo removidos os moradores do $\mathrm{BGV}$, e que neste período encontravam-se já parcialmente

\footnotetext{
${ }^{12}$ Idem.

${ }^{13}$ Idem.
} 
ocupadas pelos mesmos, encontramos informações relacionadas à precariedade do transporte coletivo que compreendia estes bairros distantes do centro urbano e da zona portuária, onde residiam anteriormente. Desta vez, são palavras atribuídas ao vereador Antonio Barros, que segundo esta ata, datada do início de outubro de 1973, a qual registrava as restrições do parlamentar sobre a qualidade das vias que ligavam os arrabaldes onde os antigos moradores passaram a viver à zona portuária onde necessitavam trabalhar:

[...] com relação aos serviços prestados por uma empresa de onibus que faz a linha para a chamada 'Vila Irmãos Coragem ${ }^{\text {'I }}$, mas agora tem ouvido as critias (sic) que a mesma vem fazendo do estado alarmante em que se encontra a estrada por onde trafegam os seus onibus. Salientou que se a Secretaria dos Transportes não tomar uma providência com urgência, dando condições, mesmo precárias, de trafegabilidade na referida estrada, o serviço de transportes coletivos poderá entrar em colapso, tal é o estado em que se encontra. $[. . .]^{15}$

Sendo assim, além dos problemas relacionados à falta de uma mínima infraestrutura das novas localidades, e de sua distancia em relação a zona portuária - mais especificamente o Bairro Getulio Vargas - os moradores estavam, nos novos terrenos, enfrentando graves problemas com o transporte coletivo, que consiste no direito e na necessidade de ir e vir de seu trabalho para prover o sustento de si mesmos e de suas respectivas famílias.

\section{Reflexões em torno da remoção das moradias do Bairro Getúlio Vargas}

Vimos a remoção das moradias do BGV em 1970 se processou numa lógica em que ocorria gradativamente um movimento de separação entre as classes e grupos sociais conforme a "função" que deveriam assumir no espaço urbano: "[...] É como se a cidade fosse demarcada por cercas, fronteiras imaginárias, que definem o lugar de cada coisa e de cada um dos moradores". (ROLNIK, I988: 40-43). O que denotava uma nítida "segregação espacial" na cidade do Rio Grande. Tais elementos nos remetem a outra característica intrínseca da segregação social em determinados territórios no meio urbano:

\footnotetext{
${ }^{14}$ Tal localidade é hoje conhecida pelo nome de Vila São João.

i5 . Ata ${ }^{\circ}$. 3499. Livro L-46. Rio Grande, IO.IO.I973.. Fl. III.
} 
[...] além dos territórios específicos e separados para cada grupo social, além da separação das funções morar e trabalhar, a segregação é patente na visibilidade da desigualdade de tratamento por parte das administrações locais. [...] As imensas periferias sem água, luz ou esgoto são evidências claras desta política discriminatória por parte do poder público, um dos fortes elementos produtores da segregação. (ROLNIK, 1988, p. 40-43).

Isso nos aponta para a necessidade de uma sociedade verdadeiramente autônoma e plenamente livre para gerir o seu território, assim como de suas territorialidades específicas, em condições plenas de acesso e desfrute equitativo dos recursos que o mesmo oferece à manutenção de suas vidas. O que no caso de um governo de cunho ditatorial, autoritário e notadamente centralizado dos anos 1970 era um horizonte distante para grandes massas e grupos sociais os mais diversos, incluindo os moradores removidos do BGV. (cf. SOUZA, 1995, p.I06)

Assim, torna-se oportuno lembrarmos que o território do BGV enquanto espaço socialmente produzido e partilhado ao longo de décadas a fio, também encerrava elementos de identificação cultural dos seus moradores que em sua maioria, além de garantirem o sustento através do trabalho no porto, compartilhavam um modo de vida e existência peculiar ao bairro. Isto porque, “[...] O espaço social, delimitado e apropriado politicamente enquanto território de um grupo, é suporte material de existência e, mais ou menos fortemente, catalisador cultural-simbólico - e, nessa qualidade, indispensável fator de autonomia”. (SOUZA, I995, p. I07-IO8). Desta forma, compreendemos que a remoção das moradias e de seus moradores para áreas muito distantes da zona portuária, ocasionou um forte desenraizamento socioeconômico e cultural que comprometeu essencialmente a organização do BGV como a "cidade dos estivadores", fazendo ruir todo um universo de sobrevivência material e identificação social há muito partilhado por seus antigos moradores.

Assim, a perspectiva crítica de Educação Ambiental é imprescindível para se pensar a relação da sociedade com o meio ambiente em que assenta a sua vida. Em outras palavras, ela impele homens e mulheres, educadores e gestores ambientais, a pensar e praticar uma relação com o território que considere a sua complexidade como um espaço produzido, partilhado e habitado por gente "de carne e osso" com seus sonhos, necessidades e aspirações. 
É deste modo que parafraseamos Vilson Sérgio de Carvalho, o qual atesta a necessidade de se produzir "novas lógicas de povoamento e ocupação dos territórios urbanos" que tenham por base um autentico diálogo entre os indivíduos e a sedimentação dos vínculos sociais entres os sujeitos que neles vivem:

[...] Somente assim, lutando pela existência de cidades onde qualidade de vida e solidariedade caminham juntas, constituindo bens inalienáveis para o(a)s citadino(a)s lidarem tanto com os benefícios que essa oferece quanto com os desafios que apresenta. (CARVALHO, 2008, p. 2I).

É justamente nesta direção que refletimos, no sentido de produzir novas sociabilidades que sejam capazes de gerar autonomia, solidariedade e cidadania para além de uma visão utilitária e essencialmente tecnicista de se conceber e planejar o território. É assim que, para transformar o mundo, devemos colocar o mundo a favor de toda a sociedade com o seu meio num sentido mais amplo:

[...] a emancipação humana, o livre manifestar das potencialidades dos seres humanos e o enriquecimento espiritual que resultem em um novo modelo civilizatório, dependem da emancipação material e do fim da alienação gerada pela mercantilização da vida e pela apropriação desigual dos bens socialmente produzidos (LOUREIRO, 2006, p. 6I).

Esta apropriação desigual dos "bens socialmente produzidos" incluiu por si mesma a apropriação desigual de um determinado território por empreendimentos industriais e comerciais durante a expansão portuária da década de 1970, como é o caso de uma área do Porto Novo que compreendia terrenos situados no Bairro Getúlio Vargas, onde moradores que desfrutavam de um modo de vida calcado em sentidos de identificação para com aquele espaço socialmente partilhado, foram removidos para áreas muito distantes de seu lócus de trabalho e desprovidas significativa infraestrutura. Acreditamos que a perspectiva de Educação Ambiental crítica e emancipatória, ao defender o "livre manifestar das potencialidades" das pessoas, reivindica que os seres humanos possam desfrutar de um território com as mínimas condições que requer um ser humano, isto é - água encanada, iluminação elétrica, transporte coletivo e condições de saúde e ambiente satisfatórias. E que além destes fatores mais concretos, tenham direito de partilhar um espaço em que possam construir seu modo de vida através de sentidos de identificação e sociabilidades baseados no exercício da autonomia e da cidadania individual e coletiva. 
É assim que Porto-Gonçalves (1995, p. 332) ressalta a necessidade de transformar a técnica e o saber tradicional de forma que sejam capazes de servir aos seres humanos como autenticas formas de sociabilidade em seu meio, fazendo emergir uma organização "genuinamente comunitária", e diríamos nós, nos diversos territórios em que homens e mulheres constroem e partilham suas vidas e de onde retiram seu sustento material e cultivam vínculos afetivos de identificação com o seu meio.

Desta forma, entendemos que a ocupação da cidade do Rio Grande, e mais especificamente a do território do Terrapleno Oeste do Porto Novo, deu-se mediante uma transformação das condições ambientais pelos estabelecimentos humanos ao longo de muitas décadas, originando um espaço socialmente produzido e partilhado pelos seus habitantes, constituindo gradativamente o território do chamado Bairro Getúlio Vargas, conhecido como "a cidade dos estivadores". E como tal, com vínculos de solidariedade e sentidos existenciais partilhados pela coletividade de moradores em torno de atividades portuárias.

Por fim, de 197I a 1973, grandes contingentes populacionais foram removidos da zona do Porto Novo - Bairro Getúlio Vargas - para subúrbios da cidade que não contavam com mínimas condições materiais de sobrevivência aos seus moradores. No entanto, muito mais do que casas de madeira em estrutura precária foram removidas daquele território, mas sim projetos de vida daqueles que ali viviam e se relacionavam com a coletividade maior de um território produzido e socialmente partilhado construído nas décadas anteriores.

\section{Referências bibliográficas}

ACSELRAD, Henri; MELLO, Cecília Campello do A.; BEZZERA, Gustavo das Neves. O que é justiça ambiental. Rio de Janeiro: Garamond, 2009.

CARVALHO, Vilson Sérgio de. Educação ambiental urbana. Rio de Janeiro: WAK Ed., 2008. CUNHA, Icaro A. da. Fronteiras da gestão: os conflitos ambientais das atividades portuárias. Rev. Adm. Pública, Rio de Janeiro, v. 40, n. 6, Dec. 2006. Disponível em: $<$ http://www.scielo.br/pdf/rap/v40n6/05.pdf $>$. Acesso 27 jul. 2010.

DOMINGUES, M.V.R.. Os conflitos de uso sócio-econômico-ambientais e o processo de caotização do espaço urbano local. Informativo SEARG. Rio Grande, março/abril de 1997.

JATOBA, Sérgio Ulisses Silva; CIDADE, Lúcia Cony Faria and VARGAS, Glória Maria. Ecologismo, ambientalismo e ecologia política: diferentes visões da sustentabilidade e do 
território. Soc. estado. [online]. 2009, vol.24, n.I, pp. 47-87. ISSN 0I02-6992. http://www.scielo.br/pdf/se/v24nI/ao4v24nI.pdf acesso 4 jun. 2010.

HARVEY, David. A Condição Pós-Moderna. Rio de Janeiro: Loyola, 1993.

LOUREIRO, C. F. B. O movimento ambientalista e o pensamento crítico. 2. ed. Rio de Janeiro: Quartet, 2006. pp.I7-78.

MARTINS, Solismar Fraga. A visão dos moradores sobre o planejamento urbano: um estudo do Bairro Santa Tereza - Rio Grande-RS. Dissertação de Mestrado. FURG, 1997. I49p. MARTINS, César Augusto Ávila. Pesquisar Moradias em Áreas Portuárias: Alguns Caminhos e Muitos Percalços. In: MARTINS, César Augusto Ávila et. al. (org.). Quintas Urbanas: Cidades e possibilidades. Rio Grande: FURG, 20II, pp. 59-III.

OLIVEIRA, Carlos Alberto de. Quem é do mar não enjoa: Memória e Experiências de Estivadores do Rio Grande/RS (I945-1993). Tese de Doutorado. PUC/São Paulo, 2000. 257 f. PORTO-GONÇALVES, Carlos Walter. Formação sócio-espacial e questão ambiental no Brasil. In: CHRISTOFOLETTI, Antonio et al. (Org). Geografia e meio ambiente no Brasil. São Paulo - Rio de Janeiro: Editora Hicitec, 1995, pp. 309-333.

ROLNIK, Raquel. O que é cidade. São Paulo: Editora Brasiliense, 1988.

SOUZA, Marcelo Lopes de. O Território: sobre espaço e poder, autonomia e desenvolvimento. In: Iná Elias de Castro et. al. (org.). Geografia: conceitos e temas. Rio de Janeiro: Bertrand Brasil, I995, pp. 77-II6. 